\title{
Powder Metallurgical Tungsten Fiber-Reinforced Tungsten
}

\author{
JASPER Bruno $0^{1, a, *}$, COENEN Jan W. ${ }^{1, b}$, RIESCH Johann ${ }^{2, c}$, \\ HÖSCHEN Till ${ }^{2, d}$, BRAM Martin ${ }^{3, \mathrm{e}}$ and LINSMEIER Christian ${ }^{1, f}$
}

${ }^{1}$ Forschungszentrum Jülich $\mathrm{GmbH}$, Institut für Energie- und Klimaforschung - Plasmaphysik, 52425 Jülich, Germany, ${ }^{2}$ Max-Planck-Institut für Plasmaphysik, 85748 Garching, Germany, ${ }^{3}$ Forschungszentrum Jülich $\mathrm{GmbH}$, Institut für Energie- und Klimaforschung - Werkstoffsynthese und Herstellungsverfahren, 52425 Jülich, Germany

ab.jasper@fz-juelich.de, bj.w.coenen@fz-juelich.de, ${ }^{c}$ johann.riesch@ipp.mgp.de, dtill.hoeschen@ipp.mpg.de, ${ }^{\mathrm{e}} \mathrm{m}$. bram@fz-juelich.de, ${ }^{\mathrm{f}}$ ch.linsmeier@fz-juelich.de

Keywords: tungsten, fusion, composite, powder metallurgy

\begin{abstract}
The composite material tungsten fiber-reinforced tungsten $\left(\mathrm{W}_{\mathrm{f}} / \mathrm{W}\right)$ addresses the brittleness of tungsten by extrinsic toughening through introduction of energy dissipation mechanisms. These mechanisms allow the release of stress peaks and thus improve the materials resistance against crack growth. $\mathrm{W}_{\mathrm{f}} / \mathrm{W}$ samples produced via chemical vapor infiltration (CVI) indeed show higher toughness in mechanical tests than pure tungsten. By utilizing powder metallurgy (PM) one could benefit from available industrialized approaches for composite production and alloying routes. In this contribution the PM method of hot isostatic pressing (HIP) is used to produce $\mathrm{W}_{\mathrm{f}} / \mathrm{W}$ samples. A variety of measurements were conducted to verify the operation of the expected toughening mechanisms in HIP $\mathrm{W}_{\mathrm{f}} / \mathrm{W}$ composites. The interface debonding behavior was investigated in pushout tests. In addition, the mechanical properties of the matrix were investigated, in order to deepen the understanding of the complex interaction between the sample preparation and the resulting mechanical properties of the composite material. First HIP $\mathrm{W}_{\mathrm{f}} / \mathrm{W}$ single-fiber samples feature a compact matrix with densities of more than $99 \%$ of the theoretical density of tungsten. Scanning electron microscopy (SEM) analysis further demonstrates an intact interface with indentations of powder particles at the interface-matrix boundary. First push-out tests indicate that the interface was damaged by HIP.
\end{abstract}

\section{Introduction}

For the first wall of a fusion reactor unique challenges are present requiring advanced materials in areas ranging from mechanical strength to thermal properties. The main challenges include wall lifetime, erosion, fuel management and safety. For the lifetime of the wall material, considerations of thermal fatigue as well as transient heat loading are crucial. Tungsten (W) is the main candidate material for the first wall of a fusion reactor as it is resilient against erosion by hydrogen isotopes, has the highest melting point of any element and shows good behavior under neutron irradiation [1]. One major disadvantage of $\mathrm{W}$ is its brittleness below the ductile-to-brittle transition temperature (DBTT), which ranges from 400-700 K [2], depending on the preparation history of the material. To circumvent the issue of brittleness when using $\mathrm{W}$, different composite approaches are investigated. One example are tungsten laminates that consist of a stack of $\mathrm{W}$ foils which are assembled as a layer composite [3]. Tungsten fiber-reinforced tungsten $\left(\mathrm{W}_{\mathrm{f}} / \mathrm{W}\right)$, as another example, utilizes fiberreinforcement and comprises of a pure $\mathrm{W}$ matrix and an interface layer around a $\mathrm{W}$ fiber $[3,4]$.

$\mathrm{W}_{\mathrm{f}} / \mathrm{W}$ incorporates extrinsic toughening mechanisms that enable energy dissipation which leads to a reduction in stress peaks at crack tips and therefore cracks can be stopped. Accordingly, even in the brittle regime, this material allows for a certain tolerance towards cracking and damage in general in comparison to conventional tungsten.

In this contribution first results of the newly developed $\mathrm{W}_{\mathrm{f}} / \mathrm{W}$ samples produced with the powder metallurgical (PM) method of hot isostatic pressing (HIP) are presented in contrast to already existing CVI $\mathrm{W}_{\mathrm{f}} / \mathrm{W}$ [4]. Those were showing extrinsic toughening mechanisms similar to those of ceramic composite materials [5]. This mechanisms will also help to mitigate effects of operational embrittlement due to neutrons and high operational temperatures $[1,5]$. 
Composition of $\mathbf{W}_{\mathbf{f}} / \mathbf{W} . A \mathrm{~W}_{\mathrm{f}} / \mathrm{W}$ composite is composed of commercially available drawn tungsten fibers, coated with an interface layer and integrated into a $\mathrm{W}$ matrix. For testing single fiber samples are used (Fig. 1Figure 1).

Different materials and material combinations were investigated as an interface material, e.g. copper, carbon and ceramics like erbia and zirconia [6].

The matrix of the first single fiber composite specimens was prepared using chemical vapor deposition (CVD). There tungsten hexafluoride $\left(\mathrm{WF}_{6}\right)$ is used, together with hydrogen, as the precursor gas. The composite is produced in a reactor in which the coated tungsten wires are aligned in the desired geometry and the precursor gas is fed through.

$$
\mathrm{WF}_{6}+3 \mathrm{H}_{2} \stackrel{300-800^{\circ} \mathrm{C}}{\longrightarrow} 6 \mathrm{HF}+\mathrm{W}
$$

The $\mathrm{WF}_{6}$ is reduced by the hydrogen in a heterogeneous surface reaction depositing the $\mathrm{W}$ metal on the interface of the fiber. In addition, multi-fiber composite samples were produced using chemical vapor infiltration (CVI), a special CVD technique. There the density of the samples can be optimized by means of the temperature profile together with the gas flow inside the reactor. Details are given in [4] and [7].
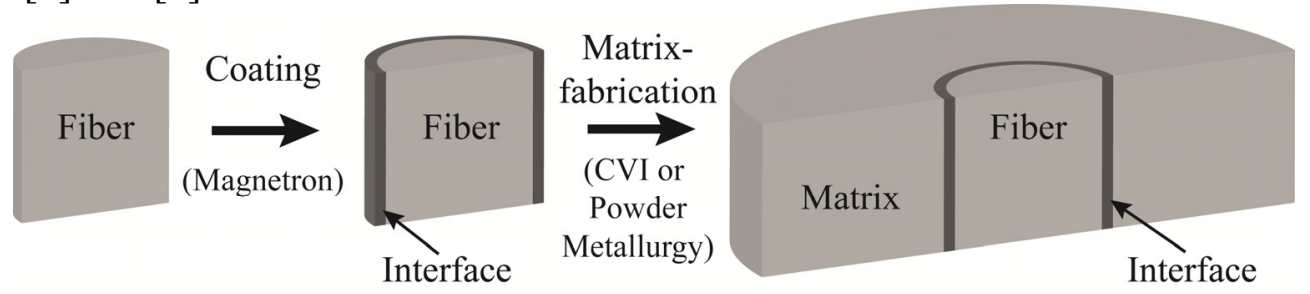

Figure 1: $\mathrm{W}_{\mathrm{f}} / \mathrm{W}$ consists of tungsten fibers, coated with an interface (e.g. $\mathrm{Er}_{2} \mathrm{O}_{3}$ ) and the $\mathrm{W}$ matrix.

Even though production by means of CVI is straightforward, application of this method to largescale prototypes and industrial application may prove difficult. In addition to further development of the CVI technology, we aim at an alternative production process that enables us to produce larger scale $\mathrm{W}_{\mathrm{f}} / \mathrm{W}$ samples in shorter time with the same properties.

For this reason HIP is chosen, where a green body of W powder is compacted at high temperatures and pressures to establish a final product close to the theoretical density. The main differences

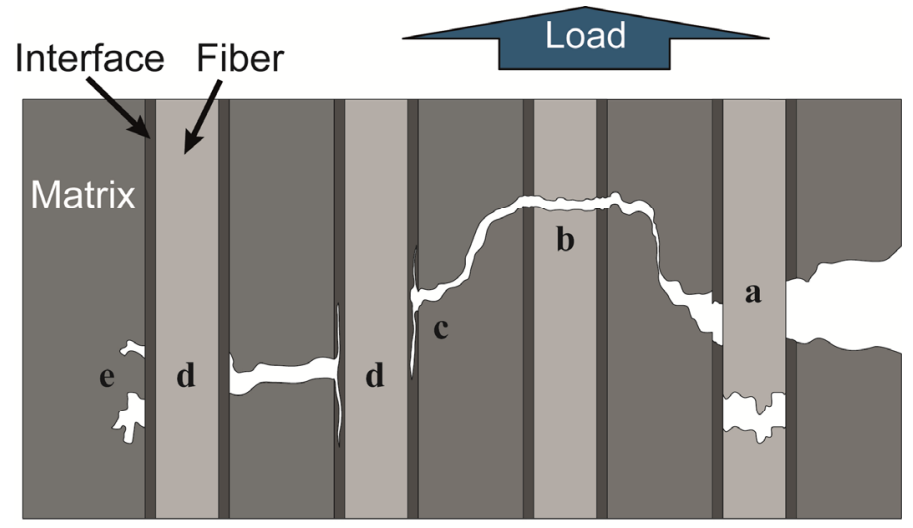

Load

Figure 2: A selection of energy dissipation mechanisms in a fiber-composite material. a) pullout of fibers, b) pull-out of matrix elements, c) crack deflection at the interface, d) crack bridging by fibers, e) crack meandering at the interface between preparation via CVI and HIP are the acting forces and temperatures. For example the matrix of CVI tungsten is assumed to grow stress free and therefore its recrystallization temperature is higher when compared to powder metallurgically processed tungsten. During CVI there are no or little forces acting on the interface-fiber complex, whereas during HIP the samples are exposed to large forces, due to the external pressure. While during CVI a high level of densification is achieved (max $99 \%$ ), it is unclear if a composite of maximum density of the matrix can be achieved via HIP.

This is particularly important since for $\mathrm{W}_{\mathrm{f}} / \mathrm{W}$ and other composites relying on extrinsic toughening mechanisms the matrix-interface debonding behavior is a crucial factor. Therefore the interface acts as a barrier layer permitting the movement of the fiber with respect to the matrix (see Fig.1). This enables the main energy dissipation mechanism in the composite, the pull-out of the fibers. Thermal stresses as well as compression of the tungsten powder, occurring 
during HIP, have to be addressed as both can damage the fiber and interface and thereby diminish the available toughening potential.

Mechanical Properties of $\mathbf{W}_{\mathbf{f}} / \mathbf{W}$. It was shown that $\mathrm{W}_{\mathrm{f}} / \mathrm{W}$ performed significantly better under mechanical loads than pure, bulk tungsten. Some of the mechanisms involved in the toughening are illustrated in Fig.2. They enable control of crack propagation through the dissipation of the respective energies by e.g. pull-out of the fibers or by crack propagation at the tailored fiber-matrix interface. Therefore, further propagation of the crack through the material is stopped [4]. Some level of interface optimization was achieved [6], further optimization with respect to the application in a fusion environment is foreseen. Most of the candidate materials are suitable to work as an interface when considering only mechanical properties, as all materials fulfill the debonding criterion [8]:

$$
\frac{\text { fracture energy of the fiber }}{\text { fracture energy of the interface }}<0.25
$$

To examine the interface behavior with respect to the debonding criterion a push-out test was used on single fiber samples [6]. 3-point bending tests on multi fiber samples were performed to investigate the mechanical behavior of the composite itself. These tests show that the fiber composite can withstand much higher loads than pure tungsten. Even after crack initiation it is still able to bear load, a clear indication that $\mathrm{W}_{\mathrm{f}} / \mathrm{W}$ is not prone to failure of full components [4]. Experiments, including synchrotron tomography, confirmed that the discussed mechanisms expected for energy dissipation in the composite system (see Fig. 2) are present [7].

\section{Experimental Procedure}

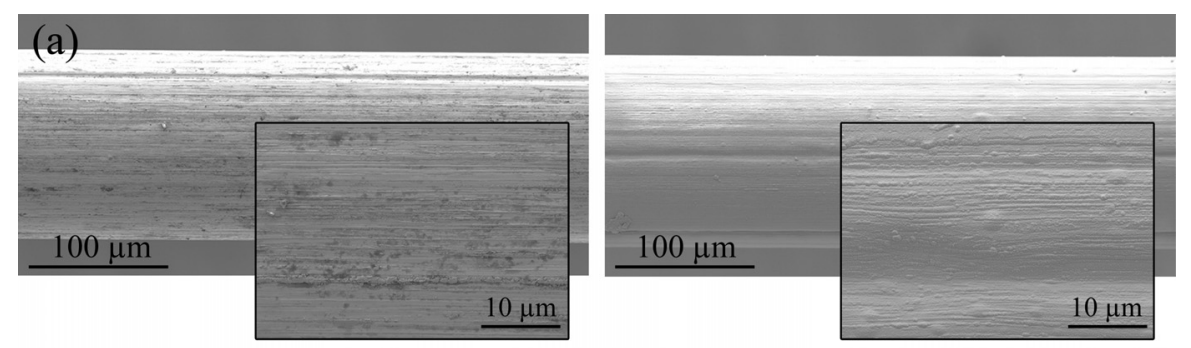

(b)

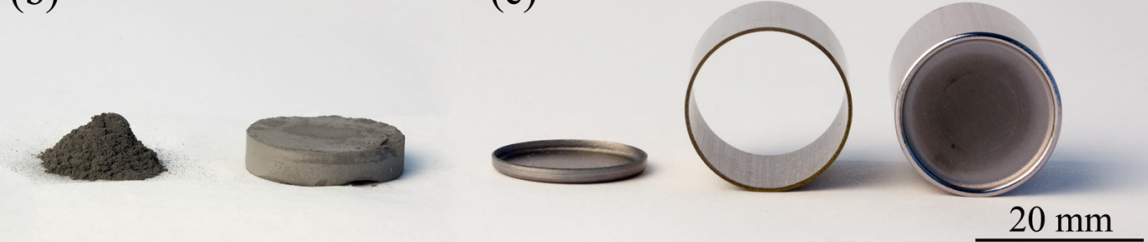

(d) (c)

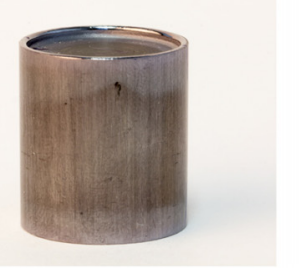

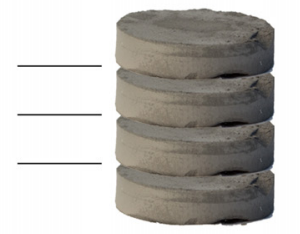

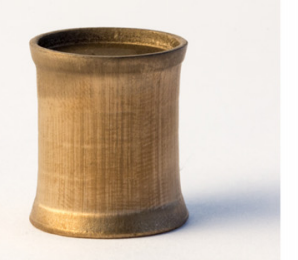

Figure 3: Pictures of the steps of the sample preparation. (a) Pure W fiber (left) and coated with erbium oxide (right) (b) W-powder and pressed tablet (c) lid, rod and electron beam welded Ta capsule (d) montage of tablets and fibers, HIP-ready capsule and HIPed capsule.
Powders. Two different powders provided by Plansee SE were chosen to produce the $\mathrm{PM} \quad \mathrm{W}_{\mathrm{f}} / \mathrm{W}$ samples. The mean particle diameter of the powders is $10.9 \mu \mathrm{m}$ and $7.7 \mu \mathrm{m}$.

Fibers. The fibers used for this work are pure tungsten with a diameter of $150 \mu \mathrm{m}$ (made available by Osram $\mathrm{GmbH}$ ) and possess a tensile strength of typically $2900 \mathrm{MPa}$ and are not stabilized against recrystallization by potassium doping, hence typically losing their ductility when exposed to temperatures above $1000^{\circ} \mathrm{C}$. For the integration into the HIP single fiber composite they are cut into pieces of $10 \mathrm{~mm}$. Due to the production via drawing of the fibers they are of even thickness, feature an elongated, fine grain structure but can possess some roughness at the surface.

Hot Isostatic Pressing (HIP) - Sample Preparation. Some steps have to be taken into account before the final densification of the specimens with HIP can take place. First, the fibers are straightened with a constant force of $50 \mathrm{~N}$. This assures a well-defined and reproducible condition of the fibers. (Fig. 3a) 
Second, a $1 \mu \mathrm{m}$ erbium oxide $\left(\mathrm{Er}_{2} \mathrm{O}_{3}\right)$ interface is deposited onto the fibers in a magnetron sputter device, using $450 \mathrm{~W}$ radio-frequency power on an erbium target in an $\mathrm{Ar}-\mathrm{O}_{2}$ atmosphere. A homogenous thickness of the interface is achieved by coating the fibers from both sides. Before coating, the fibers are plasma cleaned to assure the removal of any oxide at the surface.

Third, Tantalum with $99.9 \%$ purity (OSNABRUEGGE) is used as the capsule material, as there are no intermetallic phases between Ta and W [9]. For that purpose Ta tubes with an inner and outer diameter of $19 \mathrm{~mm}$ and $20 \mathrm{~mm}$, respectively, are cut into cylinders of $22 \mathrm{~mm}$ length. The necessary lids are stamped out of a Ta plate with a thickness of $0.5 \mathrm{~mm}$ and electron-beam welded into the Ta cylinders to form the capsules. (Fig. 3c)

The last part is the fabrication of the powder green body via die molding. For this purpose the powder is filled into a die and is subsequently compressed at $106 \mathrm{MPa}$ for $1.5 \mathrm{~min}$ into tablets of $4.3-$ $4.5 \mathrm{~mm}$ in heights and a diameter of $19 \mathrm{~mm}$ (Fig. 3b). This results in an average green density of $52 \%$ of the theoretical density of $\mathrm{W}\left(19.250 \mathrm{~g} / \mathrm{cm}^{3}\right)$. Due to this procedure, the density of neighboring tablets can differ by $0.5 \%$. Details are given in Table 1 .

One or two fibers are then placed either between two tablets or, already during die molding, inside a tablet. Since there are no visible differences in the corresponding cross-sections of the respective samples, we will not further differentiate between both types of fiber integration. Finally, the tablets are put into the capsule and the second lid is electron-beam welded onto the capsule.

Hot Isostatic Pressing (HIP) - The Process. The samples presented in this work are hot isostatically pressed (HIPed) in an argon atmosphere at $200 \mathrm{MPa}$ for $4 \mathrm{~h}$, if not indicated otherwise. Carbon heating filaments are used to achieve the desired temperatures of $1600^{\circ} \mathrm{C}, 1700^{\circ} \mathrm{C}$ and $1900^{\circ} \mathrm{C}$. The HIP run of three pure W samples, namely H701, H702 and H902 was stopped after $3 \mathrm{~h}$ $7 \mathrm{~min}$ and $28 \mathrm{~s}$, caused by a steady temperature rise in the heating zone of $\mathrm{H} 701$ and $\mathrm{H} 702$ from $1759^{\circ} \mathrm{C}$ to $1826^{\circ} \mathrm{C}$. The HIP temperature of $\mathrm{H} 902$ was not affected.

Methodology. Before analysis, all samples were wire eroded and wire cut into pieces, appropriate for the specific analysis method. In addition, after cutting all samples are polished with a Saphier 550 - Rubin 520 polishing machine (ATM GmbH) using silicon carbide paper and $3 \mu \mathrm{m}$ and $1 \mu \mathrm{m}$ diamond polishing suspensions for the final polishing steps. The etching method 98c from the ASTM E407 standard for pure tungsten is used to reveal the grain structure [10].

All scanning electron microscopy (SEM) images are either taken with a DSM 982 Gemini or a Crossbeam 540 Gemini II (Carl Zeiss AG), which is also a focused ion beam (FIB) device. The density measurements are carried out on a pure W section of the sample after Archimedes' principle with a Cubis MSA225S scale and the density measurement kit YDK01 (Satorius AG). The grain size is determined following the ASTM E112 standard [11] (see Table 1).

(a)

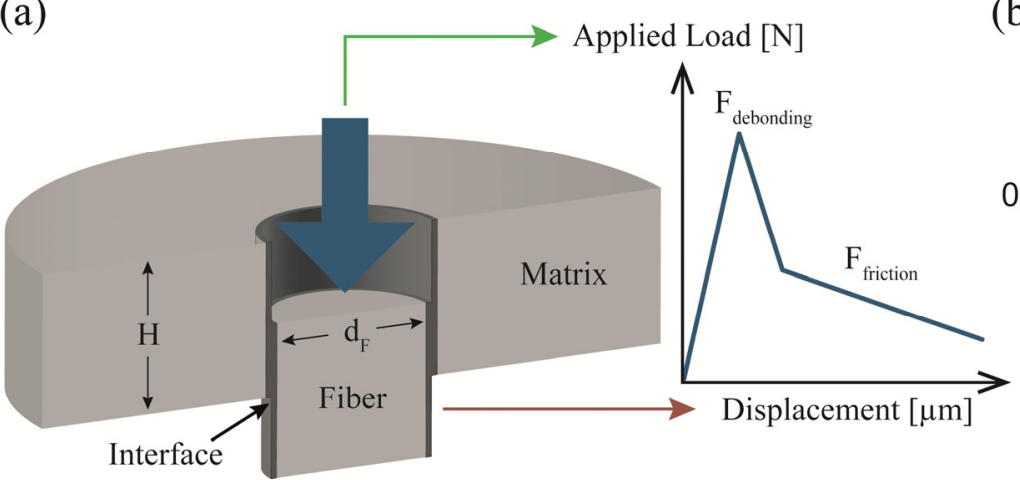

(b)

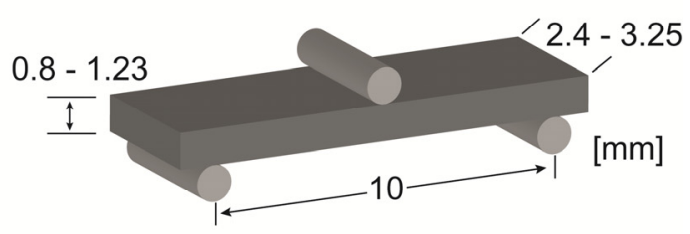

Figure 4: (a) Schematic drawing of the push-out test setup with the corresponding loaddisplacement curve. (b) Geometry of the 3-point bending test samples.

3-point bending tests for pure $\mathrm{W}$ matrix samples without fibers and push-out tests on single fiber samples are conducted using an Instron 3342 universal testing machine (Instron $\mathrm{GmbH}$ ). For 3point bending tests the support span is $10 \mathrm{~mm}$ and the traverse velocity $0.5 \mathrm{~mm} / \mathrm{min}$. The sample geometry is shown in Fig. 4b. Since W is brittle at room temperature the obtained values follow a Weibull distribution [12]: 


$$
S(x)=\exp \left(-\left(\frac{x-\Theta}{\lambda}\right)^{k}\right)
$$

Where $\mathrm{k}$ is the shape parameter, $\lambda$ the scale parameter (measure of statistical dispersion) and $\Theta$ the location parameter (y-scale intercept) of the distribution.

Whereas the 3-point bending tests are performed on pure $\mathrm{W}$ samples, in push-out tests a microindenter is carefully placed over the fiber of a polished single fiber sample and a load-displacement curve is recorded (see Fig. 4). This test gives insight into important parameters of the interface, e.g. the interfacial shear strength $\left(\tau_{\mathrm{d}}\right)$. The corresponding load-displacement curve shows two important features, the frictional part and the maximum load which the sample is able to withstand before debonding. If this is value is obtained for a number of specimens of the same batch, one can acquire $\tau_{\mathrm{d}}$ by a simple fit according to [6]:

$$
\mathrm{F}_{\max }=\pi \frac{\mathrm{d}_{\mathrm{f}} \cdot \tau_{d}}{\alpha_{2}} \tanh \left(\alpha_{2} \cdot \mathrm{H}\right)
$$

Where $F_{\max }$ is the maximum load, $d_{f}$ the diameter of the fiber, $\alpha_{2}$ the elastic constant a parameter in the shear-lag theory, $\tau_{\mathrm{d}}$ the interfacial shear strength and $H$ the thickness of the sample.

\section{Results}

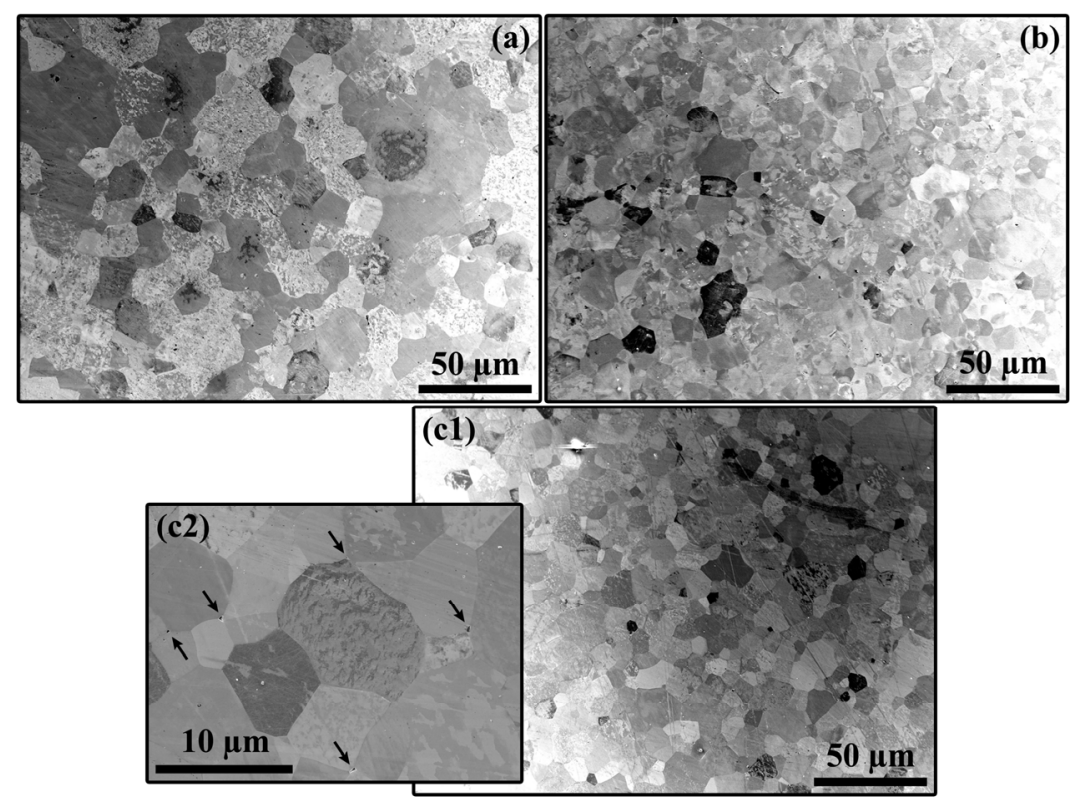

Figure 5: SEM secondary electron images of H902 (HIPed at $1900^{\circ} \mathrm{C}$ ) (a) and $1792^{\circ} \mathrm{C}$ in (b), (c1) and (c2). Arrows mark small pores.

Matrix Parameters. The samples prepared at $1600^{\circ} \mathrm{C}$ and $1700^{\circ} \mathrm{C}$ exhibit a density of $99 \%$ of the theoretical density of W $\left(19.250 \mathrm{~g} / \mathrm{cm}^{3}\right.$ [13]), or higher. In the $1900^{\circ} \mathrm{C}$ case, the matrix has a density of $97.73 \%$. Refer to Table 1 for details.

A dense matrix is also observed in SEM images of cross sections of all samples. In Fig. 5 representative SEM images are presented. Small pores, in the order of $200 \mathrm{~nm}$, are detectable at triple points of grains (see Fig. 5c2).

3-Point Bending Tests. The tests are performed for samples HIPed at $1600^{\circ} \mathrm{C}, 1700^{\circ} \mathrm{C}$ and $1900^{\circ} \mathrm{C}$. A Weibull fit was done for samples compacted at $1700^{\circ} \mathrm{C}$ and a shape parameter $\mathrm{k}$ of $5,95 \pm 1,46$, a scale parameter $\lambda$ of $744 \pm 40 \mathrm{MPa}$ and a location parameter $\Theta$ of $6,6 \pm 0,05$, were acquired (see Fig. 6). For all tested batches, the obtained bending strengths show a broad range, a clear indication for a brittle material behavior.

Fibers. In SEM analysis of cross sections it is found that the diameter of the fibers is larger after HIP by as much as $10 \%$ and coarsening of the grain structure is observed. In addition, the grain structure is coarsened since non doped fibers were used.

Interface Parameters and Fiber Push-out. SEM analysis demonstrates an intact interface with indentations of powder particles at the interface-matrix boundary (see Fig.7). In addition, FIB analysis reveals that the erbium oxide of the interface forms a complicated 3D structure between the grains of the matrix.

Push-out tests performed on single fiber $\mathrm{W}_{\mathrm{f}} / \mathrm{W}$ samples result in an interfacial shear strength $\left(\tau_{\mathrm{d}}\right)$ of $367 \pm 48 \mathrm{MPa}$. The corresponding load-displacement curves are presented in Fig. 7a. SEM analysis after the push-out test reveals failure of the matrix close to the interface region as can be seen in Fig. $7 b$. 
Table 1: A list of important properties of the samples used in this work with the respective uncertainties in parenthesis

\begin{tabular}{|c|c|c|c|c|c|c|c|}
\hline & H701 & H702 & H902 & H6F01 & H6F02 & H7F01 & H7F02 \\
\hline HIP Temperature $\left[{ }^{\circ} \mathrm{C}\right]$ & $\begin{array}{l}1759- \\
1829^{\mathrm{a}}\end{array}$ & $\begin{array}{l}1759- \\
1829^{\mathrm{a}}\end{array}$ & 1900 & 1600 & 1600 & 1700 & 1700 \\
\hline HIP duration & $3.12 \mathrm{~h}$ & $3.12 \mathrm{~h}$ & $3.12 \mathrm{~h}$ & $4 \mathrm{~h}$ & $4 \mathrm{~h}$ & $4 \mathrm{~h}$ & $4 \mathrm{~h}$ \\
\hline $\begin{array}{l}\text { Mean powder particle } \\
\text { size }[\mu \mathrm{m}]\end{array}$ & 7.7 & 10.9 & 10.9 & 10.9 & 10.9 & 10.9 & 10.9 \\
\hline $\begin{array}{l}\text { Mean grain size after } \\
\text { HIP [ } \mu \mathrm{m}]\end{array}$ & 6.(0) & 9.(6) & $10 .(5)$ & & & & \\
\hline $\begin{array}{l}\text { Average green density } \\
\text { before HIP [\%] }]^{\text {bc }}\end{array}$ & & & & $52 .(1)$ & $52 .(2)$ & 51.(7) & $51 .(9)$ \\
\hline Density after HIP [\%] $]^{\mathrm{b}}$ & 99.(4) & 99.(2) & 97.(7) & 99.(3) & $99 .(5)$ & $99 .(6)$ & $99 .(6)$ \\
\hline
\end{tabular}

${ }^{\mathrm{a}}$ Temperature was rising monotonically from $1759^{\circ} \mathrm{C}$ to $1829^{\circ} \mathrm{C}$, therefore the HIP run was stopped after $3 \mathrm{~h} 7 \mathrm{~min}$ and $28 \mathrm{~s}$, please refer to the text for more details; ${ }^{\mathrm{b}}$ In percent of the theoretical density of $\mathrm{W}\left(19.250 \mathrm{~g} / \mathrm{cm}^{3}[13]\right)$; ${ }^{\mathrm{c}}$ The local green density can vary by $0.5 \%$ from the average green density due to the preparation procedure.

\section{Discussion}

Matrix Properties. In 3-point bending tests samples of the pure W matrix showed brittle behavior as expected for $\mathrm{W}$ at room temperature or in general temperatures below the DBTT. The acquired Weibull distribution parameters with a scale parameter $\lambda$ of $744 \mathrm{MPa}$, for samples HIPed at $1700^{\circ} \mathrm{C}$, confirm this. They are also in the range of values found in literature for samples compacted under comparable conditions $[14,15]$.

Density of HIP $\mathbf{W}_{\mathrm{f}} / \mathbf{W}$. It was shown that it is possible to produce dense $\mathrm{W}$ and single fiber $\mathrm{W}_{\mathrm{f}} / \mathrm{W}$ samples via HIP. An analytical model by Redouani et al. for pure W predicts relative densities of

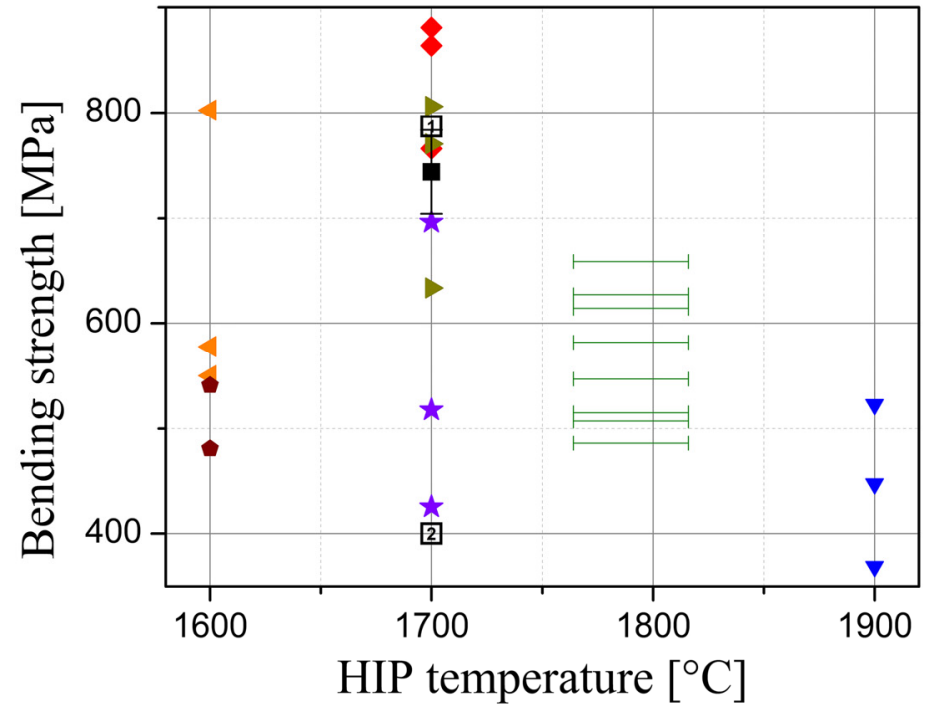

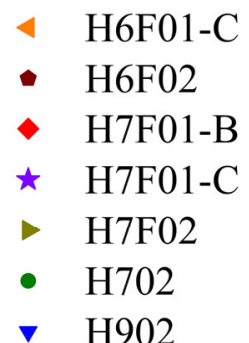

$\checkmark \mathrm{H} 902$

1 Aguirre et al.

2. Song et al.

- $\lambda=744 \mathrm{MPa}$ $\mathrm{k}=5,35$ only $94 \%$ and $97 \%$ for $1700^{\circ} \mathrm{C}$ and $1900^{\circ} \mathrm{C}$, respectively after HIP for $4 \mathrm{~h}$ at $200 \mathrm{MPa}$ [16]. This discrepancy could be explained by differences in the powder properties. The calculations by Redouani et al. are based on spherical particles of $10 \mu \mathrm{m}$ diameter, whereas in real powders, particles vary in geometry and also in size.

The lower density of Figure 6: Bending strength for samples HIPed at $1600^{\circ} \mathrm{C}, 1700^{\circ} \mathrm{C}$ and $1900^{\circ} \mathrm{C}$. The scale parameter $\lambda$ is $744 \mathrm{MPa}$ for the given samples at $1700^{\circ} \mathrm{C}$. For Details on H702 please refer to the text. the $1900^{\circ} \mathrm{C}$ sample could be attributed to micro-leaks in the Ta capsule due to the high temperature.
This would lead to argon ingress, which cannot be dissolved by the tungsten and therefore would result in pores and an incomplete densification.

$\mathrm{Er}_{2} \mathrm{O}_{3}$ Interface and Push-Out Tests. Powder particle indentations are visible in cross sections of the interface (see Fig.7). It seems therefore reasonable to assume that during HIP the powder particles of the matrix are pressed into the interface, which is in return squeezed between the grains of the matrix. This is supported by the fact that the thickness of the $\operatorname{Er}_{2} \mathrm{O}_{3}$ interface is less than the deposited $1 \mu \mathrm{m}$ before HIP and varies locally. This is a clear indication of the magnitude of the 

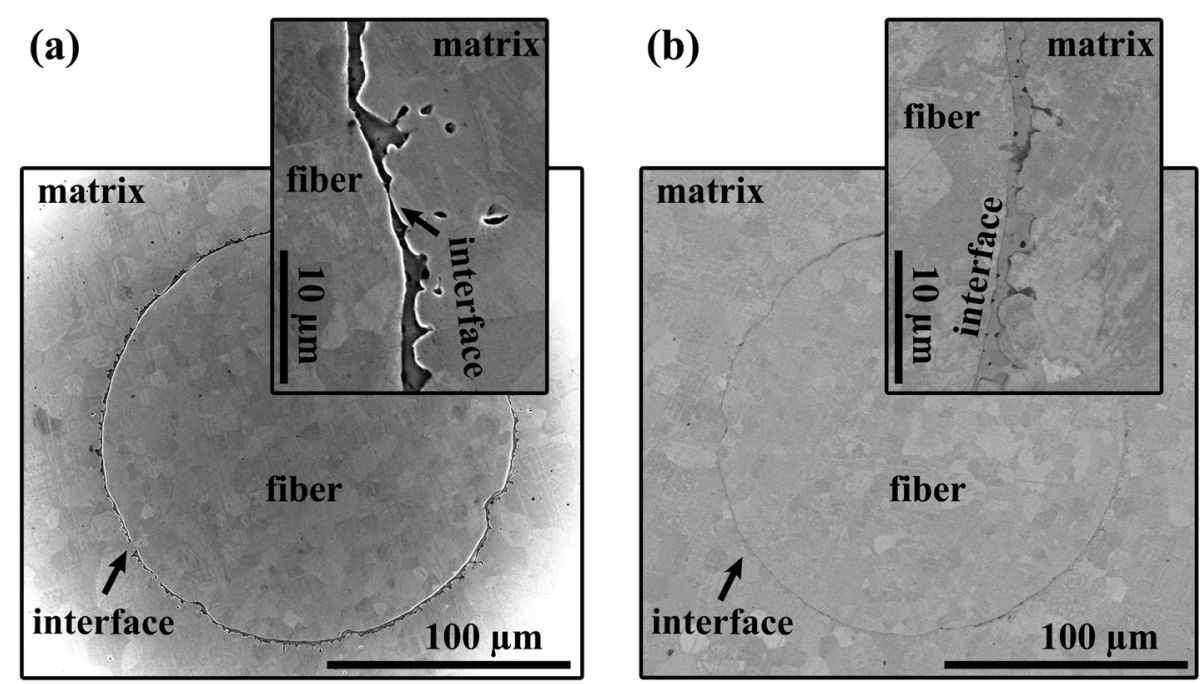

Figure 7: SEM pictures of cross section of $\mathrm{W}_{\mathrm{f}} / \mathrm{W}$ single fiber composites showing the intact but deformed interface. (a) Secondary electron (SE) image with good lateral resolution, sample HIPed at $1600^{\circ} \mathrm{C}$ (b) Back-scattered electron (BSE) signal for $\mathrm{Z}$ contrast, sample compacted at $1700^{\circ} \mathrm{C}$

$48 \mathrm{MPa}$ is in the expected range of values of $399 \mathrm{MPa}$ and $363 \mathrm{MPa}$ for an interface thickness of $1 \mu \mathrm{m}$ and $0.6 \mu \mathrm{m}$, respectively [6]. Since push out of matrix elements was observed after the pushout tests it is not clear if complete debonding of the interface took place and therefore if the obtained shear stress can be attributed solely to the interface. To make final conclusions and provide the proof of principle that indeed HIP $\mathrm{W}_{\mathrm{f}} / \mathrm{W}$ shows a toughening effect when compared to pure $\mathrm{W}$, more push-out tests of single fiber samples have to be performed.

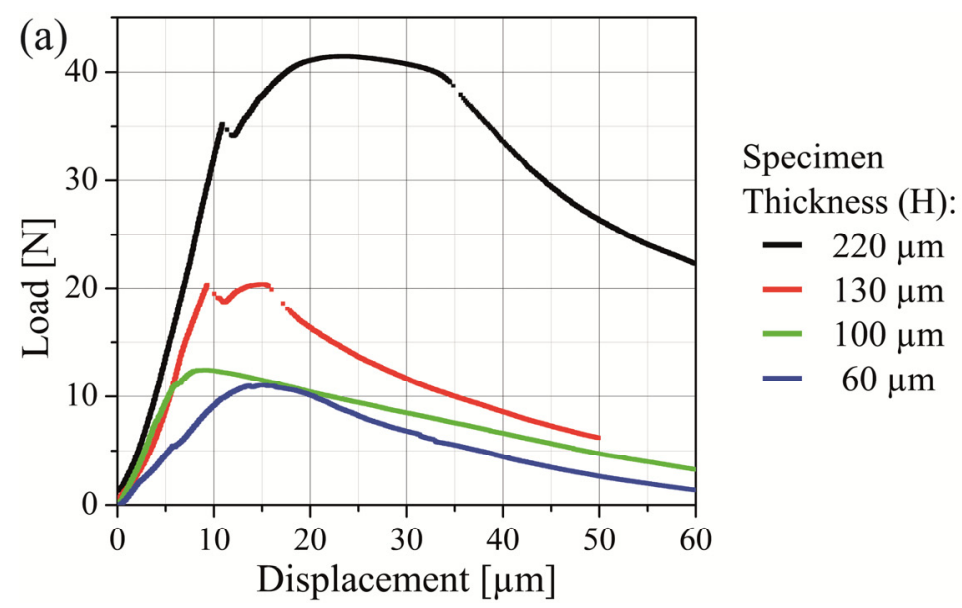

(b)

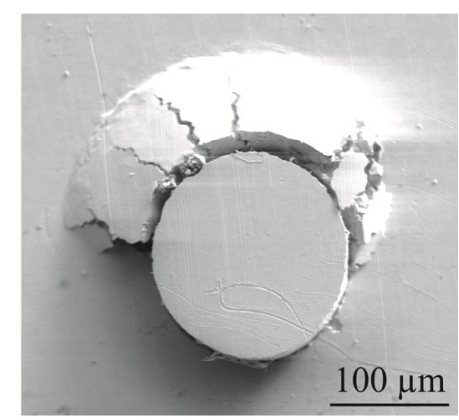

Figure 8: (a) Load-displacement curves of different specimens of one HIP single fiber $\mathrm{W}_{\mathrm{f}} / \mathrm{W}$ sample. (b) SEM picture of the pushed out fiber and failed matrix after the push-out test.

\section{Conclusion \& Outlook}

First single fiber samples of the tungsten fiber-reinforced tungsten $\left(\mathrm{W}_{\mathrm{f}} / \mathrm{W}\right)$ composite material are produced via the powder metallurgical (PM) process of hot isostatic pressing (HIP). The samples demonstrate a dense matrix that displays brittle behavior in 3-point bending tests. Scanning electron microscopy (SEM) analyses reveal a deformed but intact interface after HIP. Push-out tests are performed to verify the operation of the expected debonding mechanisms. Since failure of the matrix occurred during the tests, more have to be performed to answer this question concludingly. This will allow a final verification if complete debonding at the erbium oxide interface takes place. Summarizing, the aim of both the chemical vapor infiltrated (CVI) $\mathrm{W}_{\mathrm{f}} / \mathrm{W}$ and the $\mathrm{PM} \mathrm{W}_{\mathrm{f}} / \mathrm{W}$ development is a composite material with superior properties. Apart from matrix and fiber interaction, additional parameters come into play when fabricating a real multi-fiber composite. One 
of those parameters is the fiber volume fraction of the material which has a major influence on the resulting mechanical properties of the composite.

A minimum fiber volume fraction has to be satisfied in any fiber composite before a strengthening effect is reached [17]. In addition, there is also a maximum possible fiber volume fraction beyond which no further incorporation into the matrix is possible. Concerning the tensile strength of a fiber composite, the maximum fiber volume fraction is also the optimal fiber volume fraction due to the fact that at this point every fiber can be utilized to its maximum capability [17].

Whether CVI or PM methods will be feasible to produce a $\mathrm{W}_{\mathrm{f}} / \mathrm{W}$ component has to be demonstrated by future experiments and further development.

\section{Acknowledgements}

A special thank goes to F. Koch, P. Zhao, W. Behr, R. Steinert and B. Coenen.

This work has been carried out within the framework of the EUROfusion Consortium and has received funding from the Euratom research and training programme 2014-2018 under grant agreement No 633053. The views and opinions expressed herein do not necessarily reflect those of the European Commission.

\section{References}

[1] R. Lässer et al., Structural materials for DEMO: The EU development, strategy, testing and modelling, Fusion Engineering and Design, 82 (2007) 511-520

[2] H. Bolt et al., Plasma facing and high heat flux materials-needs for ITER and beyond, Journal of Nuclear Materials, 307-311 (2002) 43-52

[3] J. Reiser et al., Tungsten foil laminate for structural divertor applications - Basics and outlook, Journal of Nuclear Materials, 423 (2012) 1-8

[4] J. Riesch et al., Enhanced toughness and stable crack propagation in a novel tungsten fibrereinforced tungsten composite produced by chemical vapour infiltration, Phys. Scr. T159 (2014) $014031(7 \mathrm{pp})$

[5] T. Hinoki et al., Silicon Carbide and Silicon Carbide Composites for Fusion Reactor Application, Materials Transactions, 54 (2013) 472-476

[6] J. Du, A feasibility study of tungsten-fiber-reinforced tungsten composites with engineered interfaces, Ph.D. Thesis, Technische Universität München, 2011

[7] J. Riesch et al., In-situ synchrotron tomography estimation of toughening effect by semi-ductile fibre reinforcement in a tungsten fibre-reinforced tungsten composite system, Acta Mat., 61 (2013) 7060-7071

[8] M.-Y. He, J.W. Hutchinson, Crack deflection at an interface between dissimilar elastic materials, International Journal of Solids and Structures, 25 (1989) 1053-1067

[9] B. Predel, Ta-W (Tantalum-Tungsten), Madelung, O. (ed.), SpringerMaterials - The LandoltBörnstein Database, DOI: 10.1007/10551312_2793 (15.02.02)

[10] ASTM Standard E407, 1999, "Standard Practice for Microetching Metals and Alloys", ASTM International, West Conshohocken, PA, 1996

[11] ASTM Standard E112, 1996e3, "Standard Test Methods for Determining Average Grain Size", ASTM International, West Conshohocken, PA, 1996

[12] W. Weibull, A Statistical Theory of the Strength of Materials, Ingeniors Vetenskaps Akademien, 151 (1939)

[13] E. Lassner, W.-D. Schubert, Tungsten - Properties, Chemistry, Technology of the Element, Alloys and Chemical Compounds, Kluwer Academic/Plenum Publishers, 1999

[14] M.V. Aguirre et al., Mechanical Behavior of W- $\mathrm{Y}_{2} \mathrm{O}_{3}$ and W-Ti Alloys from $25^{\circ} \mathrm{C}$ to $1000^{\circ} \mathrm{C}$, Metallurgical and Materials Transactions A, 40 (2009) 2283-2290

[15] G.-M. Song, Y.-J. Wang, Y. Zhou, Thermomechanical properties of TiC particle-reinforced tungsten composites for high temperature applications, Int. J. of Refractory Metals and Hard Mat.,

$21(2003) 1-12$ 
[16] L. Redouani, S. Boudrahem, Hot isostatic pressing process simulation: application to metal powders, Canadian Journal of Physics, 90 (2012) 573-583

[17] N. Pan, Theoretical determination of the optimal fiber volume fraction and fiber-matrix property compatibility of short fiber composites, Polymer Composites, 14 (1993) 85-93 